\title{
Diálogos em isolamento: observação das experiências de mulheres com deficiência no Instagram durante a pandemia
}

\author{
Dialogues in isolation: observation of the experiences of women with \\ disabilities on Instagram during the pandemic
}

\section{Diálogos en aislamiento: observación de las vivencias de mujeres con discapacidad en Instagram durante la pandemia}

Fatine Conceição Oliveira ${ }^{1, a}$

fatineco@email.com | https://orcid.org/oooo-0002-8823-7314

Camila Maciel Campolina Alves Mantovani ${ }^{1, b}$

camilamm@gmail.com | https://orcid.org/0000-0002-9922-6848

\footnotetext{
${ }^{1}$ Universidade Federal de Minas Gerais, Faculdade de Filosofia e Ciências Humanas. Belo Horizonte, MG, Brasil.

a Mestrado em Comunicação Social pela Universidade Federal de Minas Gerais.

${ }^{\text {b }}$ Doutorado em Ciência da Informação pela Universidade Federal de Minas Gerais.
}

\section{RESUMO}

Em 2020, o mundo teve como principal desafio adaptar-se diante de uma mudança estrutural nas relações cotidianas, incluindo novos hábitos com o uso de máscaras, protocolos de segurança sanitária e o isolamento social como medidas de enfrentamento à pandemia da Covid-19. Partindo do entendimento de que situações de crise, em escala global, podem influir no agravamento de desigualdades sociais, políticas e econômicas dos sujeitos, vemos que, no Brasil, a falta de informações confiáveis sobre o coronavírus e a ausência de políticas públicas que visem garantir o acesso da população à saúde contribuem fortemente para aumentar o risco de contaminação e, consequentemente, o número de mortes pela Covid-19. Diante desse contexto, nos propusemos a acompanhar a participação do Coletivo Feminista Helen Keller na campanha \#CompartilheInformação \#CompartilheSaúde realizada no Instagram pela ONG Artigo 19, no intuito de observar suas redes de apoio e diálogos realizados em encontros virtuais por meio de lives e webinários com temas relacionados a saúde, autocuidado e violência contra as mulheres com deficiência. Nesse exercício, foi possível perceber como as dinâmicas de mobilidade e imobilidade, que se alternam em ambientes reais e digitais, conformaram-se para criar espaços de diálogos e interações nesses contextos.

Palavras-chave: Comunicação; Direitos humanos; Pessoas com deficiência; Mobilidade; Saúde. 


\section{ABSTRACT}

In 2020, the main challenge for the world was to adapt to a structural change in daily relations, including new habits with the use of masks, health security protocols and social isolation as measures to combat the Covid-19 pandemic. Starting from the understanding that crisis situations, on a global scale, can influence the worsening of social, political and economic inequalities of the subjects, we see that, in Brazil, the lack of reliable information about the coronavirus and the absence of public policies that aim to guarantee the population's access to health contributes strongly to increase the risk of contamination and, consequently, the number of deaths by Covid-19. Given this context, we set out to follow the participation of the Feminist Collective Helen Keller in the campaign \#CompartilheInformação \#CompartilheSaúde carried out on Instagram by the NGO Artigo 19, to observe their support networks and dialogues held in virtual meetings through lives, webinars with themes related to health, self-care and violence against women with disabilities. In this exercise, it was possible to see how the dynamics of mobility and immobility, which alternate in real and digital environments, conformed to create new spaces for dialogues and interactions in these contexts.

Keywords: Communication; Human rights; People with disabilities; Mobility; Health.

\section{RESUMEN}

En 2020, el principal desafío para el mundo fue adaptarse a un cambio estructural en las relaciones cotidianas, incluyendo nuevos hábitos con el uso de máscaras, protocolos de seguridad en salud y aislamiento social como medidas para enfrentar la pandemia Covid-19. Partiendo del entendimiento de que situaciones de crisis, a escala global, pueden incidir en el agravamiento de las desigualdades sociales, políticas y económicas de los sujetos, vemos que, en Brasil, la falta de información confiable sobre el coronavirus y la ausencia de políticas públicas que el objetivo sea de garantizar el acceso de la población a la salud contribuyen fuertemente a incrementar el riesgo de contaminación y, en consecuencia, el número de muertes por Covid-19. Ante este contexto, nos propusimos seguir la participación del Colectivo Feminista Helen Keller en la campaña \#CompartilheInformação \#CompartilheSaúde realizada en Instagram por la ONG Artículo 19, con el fin de observar sus redes de apoyo y diálogos realizados en encuentros virtuales a través de lives, webinars con temas relacionados con la salud, el autocuidado y la violencia contra las mujeres con discapacidad. En este ejercicio se pudo ver cómo las dinámicas de movilidad e inmovilidad, que se alternan en entornos reales y digitales, se conforman para crear nuevos espacios de diálogo e interacción en estos contextos.

Palabras clave: Comunicación; Derechos humanos; Personas con discapacidad; Movilidad; Salud.

Contribuição dos autores:

Concepção e desenho do estudo: Fatine Conceição Oliveira e Camila Maciel Campolina Alves Mantovani.

Aquisição, análise ou interpretação dos dados: Fatine Conceição Oliveira.

Redação do manuscrito: Fatine Conceição Oliveira e Camila Maciel Campolina Alves Mantovani. Revisão crítica do conteúdo intelectual: Camila Maciel Campolina Alves Mantovani.

Declaração de conflito de interesses: não há.

Fontes de financiamento: não houve.

Considerações éticas: não há.

Agradecimentos/Contribuições adicionais: não há.

Histórico do artigo: submetido: 11 mar. 2021 | aceito: 26 jul. 2021 | publicado: 31 ago. 2021.

Apresentação anterior: não há.

Licença CC BY-NC atribuição não comercial. Com essa licença é permitido acessar, baixar (download), copiar, imprimir, compartilhar, reutilizar e distribuir os artigos, desde que para uso não comercial e com a citação da fonte, conferindo os devidos créditos de autoria e menção à Reciis. Nesses casos, nenhuma permissão é necessária por parte dos autores ou dos editores. 
No começo parecia um filme de ficção científica. As ruas vazias, janelas fechadas, olhares desconfiados e o noticiário relatando o improvável. O mundo havia parado por causa de um vírus. O coronavírus foi identificado pela primeira vez em dezembro de 2019, na cidade de Wuhan, na China (OPAS, 2020). O aumento do número de casos foi exponencial. Primeiro, contavam-se as semanas, depois os dias e de repente as horas pareciam minutos para cada vida que partia.

No início da pandemia, tanto o fechamento das fronteiras dos países quanto o isolamento social foram alguns dos protocolos de segurança mais recomendados pela Organização Mundial de Saúde (OMS) como medidas para controlar o risco de contaminação pela Covid-19 e, consequentemente, o número de vítimas.

A pandemia e seus desdobramentos passaram, então, a ocupar não apenas o noticiário, como também a comunicação científica, suscitando análises e reflexões que se davam em diversos campos do conhecimento. As dimensões biológicas, políticas, sociais, culturais, econômicas e éticas, que atravessam essa grave situação mundial, apontam-nos para sua complexidade e para a necessidade de um olhar mais amplo, mas que também não perca de vista as especificidades e nuances.

Um aspecto que nos chama a atenção nas questões trazidas pela pandemia e o isolamento social relaciona-se às dinâmicas de mobilidade e imobilidade, tanto em termos da circulação física de pessoas, quanto aquela que ocorre por meio dos fluxos informacionais. No que concerne ao primeiro aspecto, devido à intensa movimentação de pessoas pelo planeta, o vírus teve sua potencialidade de contágio ampliada a uma escala global. Diante disso, uma das primeiras medidas para conter sua disseminação foi criar restrições à circulação de pessoas. Nesse cenário, a mobilidade, que não podia mais se fazer de forma física, foi direcionada para os ambientes digitais, nos quais os sujeitos, em princípio, poderiam se deslocar em forma de fluxos e interações.

Assim, muitas atividades e relações que mantínhamos nos ambientes físicos foram, de forma um tanto abrupta, migrando para os ambientes digitais. Na impossibilidade de nos movermos pelos ambientes físicos, fomos nos fazendo fluxo para, assim, darmos conta de sustentar uma série de atividades e relações que nos eram fundamentais. Entretanto, cabe ressaltar que a mobilidade nos ambientes digitais foi percebida e vivenciada de diferentes maneiras. Enquanto para alguns foi possível um movimento mais rápido e frequente, tendo em vista favoráveis condições estruturais (equipamento, infraestrutura de rede e outros) e cognitivas de acesso, permitindo uma presença mais intensa nas redes sociais digitais, para outros, mover-se foi (e ainda é) algo turbulento, tendo em vista as 'rugosidades"' - condições preexistentes em cada situação (recursos materiais, organização social, econômica e cultural) - que se interpõem a esse espaço de fluxos, como bem nos lembra Santos (2003, 2012).

No que se refere ao trabalho, apesar de algumas empresas terem realizado mudanças em sua organização, adotando o modelo home office, o índice de desemprego aumentou durante a pandemia, especialmente, para as atividades que requerem a presença física do trabalhador. De acordo com o site Nexo (ROUBICEK, 2021), os trabalhadores do grupo informal - ambulantes, entregadores e motoristas de aplicativo - foram os primeiros impactados com a crise sanitária. Já no grupo dos formais, os trabalhadores com carteira assinada foram afetados durante os meses de junho e agosto de 2020. O auxílio emergencial, benefício concedido pelo Governo Federal com valor inicial de $\mathrm{R} \$ 600,00$, contribuiu para que muitas famílias pudessem, por algum tempo, permanecer em casa, cumprindo as medidas de prevenção, sem se verem sem nenhum tipo de renda.

No entanto, sabemos que tais iniciativas não foram suficientes para reduzir os impactos causados pela pandemia. No que concerne à violência doméstica, por exemplo, as medidas de isolamento contribuíram para o agravamento da situação ao submeter mulheres, jovens, crianças, idosos e pessoas com deficiência de diferentes classes, raça e sexualidade a permanecerem no mesmo ambiente que seus agressores, em sua maioria membros da mesma família ou pessoas próximas. 
Diante deste cenário, Sheller (2018) nos chama a atenção para o valor da mobilidade, da importância de se dispor daquilo que ela conceitua como "capital de rede" (p. 70), formado por aspectos econômicos, políticos e culturais que permitem a determinados sujeitos o livre acesso aos espaços físicos públicos ou privados, como também a direitos como saúde de qualidade, moradia e segurança.

As mobilidades são sempre contingentes, contestadas e performativas. As mobilidades nunca são gratuitas, mas de várias formas sempre são canalizadas, rastreadas, controladas, governadas, vigiadas e desiguais - estratificadas por gênero, raça, etnia, classe, casta, cor, nacionalidade, idade, sexualidade, deficiência etc. tudo de fato experimentado como efeitos de mobilidades desiguais. (SHELLER, 2018, p. 31, tradução nossa). ${ }^{1}$

Em diálogo com a autora, pretendemos, neste ensaio, traçar uma observação sobre a realidade das mulheres com deficiência durante o período da pandemia, tendo como ponto de partida as ações de conscientização realizadas no perfil do Coletivo Feminista Helen Keller, no Instagram, em parceria com o perfil do projeto Artigo 19. Durante essas ações, foram apresentados alguns webinários com nomes importantes do movimento social das pessoas com deficiência e com algumas integrantes do Coletivo, debatendo aspectos relacionados à saúde das mulheres com deficiência, à violência doméstica e à acessibilidade digital.

Interessa-nos, portanto, refletir acerca das experiências dessas mulheres, organizadas a partir de suas (i)mobilidades emergentes durante a pandemia, bem como seus atravessamentos com outras categorias sociais, as conexões estabelecidas na rede social digital e os diálogos em circulação. Para isso, apresentaremos, brevemente, a trajetória de luta das pessoas com deficiência, a contribuição do campo de estudo da deficiência para emancipação social do movimento e as implicações do capacitismo na vivência deste grupo.

Começando esse nosso percurso, retornaremos em alguns momentos da história de luta das pessoas com deficiência, partindo de suas movimentações nos anos 1970, nos Estados Unidos e Reino Unido, influenciadas pelas mudanças conquistadas por diferentes grupos sociais após se organizarem a favor dos direitos raciais, sexuais e feministas. Antes deste período, era vigente um modo de categorizar os sujeitos com deficiência a partir, exclusivamente, de pressupostos biomédicos de correção corporal, cura, reabilitação ou reclusão institucional em hospitais e clínicas, os quais reforçavam imaginários sociodiscursivos (PESSOA, 2018, p.40) presentes nos estereótipos e comportamentos preconceituosos.

Diante do incômodo causado por essa perspectiva, que enxergava na deficiência um problema a ser corrigido, um grupo de teóricos com deficiência reuniu-se para elaborar um campo de estudos que formaria um novo modo de classificação dos corpos com deficiência. Esse encontro, segundo Débora Diniz (2007), se deu a partir de estratégias organizadas para contornar as distâncias provocadas pelas instituições. Em ambiente de extremo controle e vigilância, encontraram brechas para viabilizar a comunicação entre eles, permitindo um longo (e secreto) debate conceitual em cartas trocadas durante quatro anos. Assim, surgiria a organização política chamada UPIAS (Union of Physically Impaired Against Segregation), responsável por elaborar um modelo conceitual para a deficiência que, apesar de reconhecer as contribuições médicas para identificar as lesões no corpo, minimizar dores e promover o cuidado, apontava para a relação opressiva das estruturas e barreiras sociais sobre os indivíduos, impedindo-os de ter uma participação autônoma na sociedade (DINIZ; MEDEIROS; SQUINCA, 2007, p. 7-8).

Dessa maneira, o modelo social, como ficou conhecido, pressupunha que, ao adotar medidas políticas, econômicas e culturais para retirada dos obstáculos físicos nos espaços públicos e privados, seria possível

1 "Mobilities are always contingent, contested, and performative. Mobilities are never free but are in various ways always channeled, tracked, controlled, governed, under surveillance and unequal - striated by gender, race, ethnicity, class, caste, color, nationality, age, sexuality, disability, etc., which are all in fact experienced as effects of uneven mobilities.” 
estimular a construção de uma postura mais inclusiva na sociedade, permitindo, assim, que as pessoas com deficiência experimentassem mais liberdade e autonomia para tomada de decisões, participação social e oportunidade de trabalho.

Entretanto, algumas vivências confrontam o modo como os sujeitos compreendem suas realidades. Ainda que pertençam a um mesmo grupo social, compartilhem as mesmas lutas e pautas, existem espaços onde as experiências se diferem. Por essa razão, por mais que o modelo social tenha vigorado durante muitos anos, um grupo de feministas com e sem deficiência chamou atenção para a importância do cuidado, como direito humano fundamental para algumas pessoas que, em virtude de suas patologias, não possuem mobilidade sem a presença de um terceiro.

Durante quase duas décadas, a premissa da independência como um valor ético para o modelo social manteve- se livre de críticas. Os primeiros teóricos do modelo social eram homens, em sua maioria portadores de lesão medular, que rejeitavam não apenas o modelo médico curativo da deficiência, como também toda e qualquer perspectiva caritativa perante a deficiência. Princípios como o cuidado ou os benefícios compensatórios para o deficiente não estavam na agenda de discussões, pois se pressupunha que o deficiente seria uma pessoa tão potencialmente produtiva como o não-deficiente, sendo apenas necessária a retirada das barreiras para o desenvolvimento de suas capacidades. (DINIZ; MEDEIROS; SQUINCA, 2007, p. 26).

Além dos princípios apresentados pela autora, as feministas ampliaram as discussões da deficiência para abarcar outras formas de imobilidade provocadas por algumas doenças crônicas, popularmente conhecidas como deficiências invisíveis, como também as necessidades e cuidados típicos do processo de envelhecimento. Outro ponto importante debatido pelas feministas foi o agravamento das desigualdades provocadas pela relação com outras formas de opressão, como machismo, racismo, LGBTfobia e outros.

Por fim, propuseram a noção de interdependência para contribuir e, assim, sugerir um segundo modelo social, trazendo outra perspectiva ao valor conferido à independência e autonomia, defendidas pelos primeiros teóricos do modelo social. Trata-se de uma revisão da primeira perspectiva sobre a deficiência, uma vez que alguns dos princípios adotados foram definidos a partir das vivências dos autores, a maioria homens, com necessidades que não demandavam o mesmo tipo de cuidado que outras pessoas com deficiência, em especial as mulheres (DINIZ; MEDEIROS; SQUINCA, 2007, p. 27).

Em 2008, a Organização das Nações Unidas (ONU) organizou a Convenção dos Direitos das Pessoas com Deficiência no intuito de estabelecer metas e objetivos para garantir os direitos das pessoas com deficiência nos países participantes. No artigo 6 do documento há menção às múltiplas opressões e discriminações às quais mulheres e meninas com deficiência estariam sujeitas, caso os países membros não assegurem condições de segurança, saúde, educação, emprego e moradia para seu desenvolvimento e empoderamento.

Em 2015, o Brasil sanciona a Lei Brasileira de Inclusão (LBI) com a intenção de decretar os direitos das pessoas com deficiência para garantir sua participação na sociedade em condições de igualdade. De acordo com a lei,

Considera-se pessoa com deficiência aquela que tem impedimento de longo prazo de natureza física, mental, intelectual ou sensorial, o qual, em interação com uma ou mais barreiras, pode obstruir sua participação plena e efetiva na sociedade em igualdade de condições com as demais pessoas. (BRASIL, 2015).

Ao enfatizar a interação do corpo com barreiras físicas, atitudinais, econômicas e sociais, a lei adota a perspectiva do modelo social, sem ignorar a relevância da medicina para classificação da deficiência. No país, de acordo com IBGE (2010), cerca de 6,7\% da população possuem algum tipo de deficiência, e muitas delas criam algum tipo de restrição ao movimento e, consequentemente, ao acesso a determinados 
lugares e serviços. Sendo assim, boa parte desse grupo já enfrentava algum tipo dificuldade relativa às dinâmicas do movimento e, em certa medida, já lidavam, bem antes da Covid-19, com os desafios trazidos pelo isolamento social.

No começo da pandemia, as manchetes dos principais jornais do país alertavam para os riscos da doença, destacando repetidamente a angústia dos médicos diante da falta de ar provocada pela doença. Aos poucos, nós nos habituamos a falar de respiradores, medicamentos, vírus e suas variantes, assumindo uma nova gramática verbal, mas também corporal, na medida em que adotamos novos comportamentos e cuidados com a higiene. $\mathrm{O}$ ato de lavar as mãos se tornaria um ritual com outros movimentos, ritmos e acessórios, assim como o corpo precisaria adotar outras formas de ocupar os espaços, lidar com as distâncias e com os sujeitos dentro de casa.

As novas possibilidades do movimento despertaram o interesse de estudiosos, que passaram a endereçar essas transformações a partir do arcabouço conceitual e metodológico do paradigma da mobilidade, desenvolvido por Urry e Sheller (2001, 2007). Num livro publicado em 2007, e ainda sem tradução para o português, Urry discorreu sobre determinadas formas de mobilidade que, na sua perspectiva, produzem e organizam a vida social, atuando de maneira interdependente.

Primeiramente, teríamos a 'mobilidade corpórea' dos sujeitos, que se dá a partir de diferentes motivações e necessidades de deslocamentos. Outro tipo de mobilidade seria a dos 'objetos físicos', que se caracteriza, primordialmente, pelas transações comerciais, no entanto, os objetos também podem se mover com os sujeitos e/ou de um sujeito para o outro sem que isso envolva negociações financeiras. Há também a 'mobilidade imaginativa', que acontece por meio de imagens de lugares e pessoas em diferentes mídias. Por fim, as duas últimas mobilidades que o autor caracteriza em seu texto e que talvez sejam a que mais estejamos experienciando nos últimos tempos são: a 'mobilidade virtual', que se dá a partir das redes digitais e que acontece em tempo real; e a 'mobilidade comunicativa', que ocorre por meio de mensagens entre pessoas, a partir de diferentes textualidades e dispositivos (URRY, 2007).

Porém, mais que promover uma caracterização do movimento, é preciso compreender suas assimetrias, decorrentes de questões culturais, econômicas, sociais e de infraestrutura. Sendo assim, Mimi Sheller (2018) propõe examinar a mobilidade, em momentos de crise global, de forma interseccional.

Novas formas de estudar as mobilidades têm por foco a atenção em práticas corporais e materiais de movimento, mobilidades digitais e comunicativas, as infraestruturas e os sistemas de governança que permitem ou desabilitam o movimento e as representações, ideologias e significados ligados ao movimento e à imobilidade. A virada das mobilidades também enfatiza a relação de tais mobilidades com imobilidades ou amarras, incluindo as dimensões políticas e éticas da mobilidade assimétrica. A pesquisa de mobilidades preocupa-se não apenas em traçar o surgimento histórico de regimes, tecnologias e práticas de mobilidade modernos, mas também em abordar de forma crítica questões políticas contemporâneas, como movimentos para mobilidade sustentável, igualdade racial e direitos de mobilidade de migrantes, e ajudar a construir ativamente todos os dias capacidades de mobilidade, a partir do acesso físico ao espaço público da cidade e às infraestruturas de transporte e comunicação. (SHELLER, 2018, p. 32-33, tradução nossa). ${ }^{2}$

De acordo com a perspectiva trazida pela autora, os eventos globais atuais parecem trazer à tona essa variedade de tipos de conexão entre indivíduos e sociedade. E isso nos leva a refletir sobre as

\footnotetext{
2 "New ways of studying mobilities focus attention on embodied and material practices of movement, digital and communicative mobilities, the infrastructures and systems of governance that enable or disable movement, and the representations, ideologies, and meanings attached to both movement and stillness. The mobilities turn also emphasizes the relation of such mobilities to associated immobilities or moorings, including the political and ethical dimensions of uneven mobility. Mobilities research is concerned not only with tracing the historical emergence of modern mobility regimes, technologies, and practices, but also critically addressing contemporary political issues such as movements for sustainable mobility, racial equity, and migrants' mobility rights, and helping to actively build everyday mobility capabilities such as physical access to the public space of the city and to transportation and communication infrastructures."
} 
possibilidades de interação e trocas em situações que tornam os sujeitos mais vulneráveis. Do ponto de vista da mobilidade, podemos ficar vulneráveis pela falta de serviços de transporte público, por exemplo, ou pelas próprias condições do corpo nas suas situações mais básicas de movimento. Tais discussões também podem estar relacionadas aos conceitos apresentados por Kaufmann, Bergman e Joye (2004) sobre mobilidade e motilidade. Ao apontarem três elementos interdependentes de mobilidade - acesso, competência e apropriação -, os autores refletem sobre como eles estão "fundamentalmente ligados a processos e estruturas sociais, culturais, econômicos e políticos dentro dos quais a mobilidade está inserida e é propagada (KAUFMANN; BERGMAN; JOYE, 2004, p. 751, tradução nossa)33.

Nesse sentido, tecnologias móveis e alguns aplicativos de redes sociais já costumavam ser considerados por algumas pessoas com deficiência como uma via para se reunirem, compartilhando seu cotidiano e trocando experiências entre si. Com a chegada da pandemia, essas dinâmicas se intensificaram, tornando os espaços de fluxos uma alternativa viável e segura para as trocas entre os sujeitos.

Essa quantidade de conexões, que dificilmente o ator terá na vida off-line, influencia várias coisas. Pode, assim, torná-lo mais visível na rede social, pode tornar as informações mais acessíveis a esse ator. Pode, inclusive, auxiliar a construir impressões de popularidade que transpassem ao espaço off-line. (RECUERO, 2009, p. 107).

Os dispositivos tecnológicos tornaram possível a efetivação de formas de sociabilidade independentes do tempo e do espaço, mas, nas discussões iniciais, havia a preocupação com o esvaziamento do caráter das interações já que a ausência de signos de fisicalidade poderia fragilizar o curso do diálogo. No entanto, com o desenvolvimento das tecnologias, as interações mediadas começaram a ganhar diversos elementos que estimulariam as trocas entre os sujeitos.

Segundo Costa (2005), é preciso compreender os novos alcances para laços afetivos construídos nas comunidades que se formam no ambiente virtual, pois "na maior parte dos casos não seria possível fazer entre "próximos', simplesmente porque as redes locais são por definição limitadas no tempo e espaço" (COSTA, 2005, p. 247).

Sentimentos como confiança, reconhecimento e respeito sustentam essas conexões, estimulando em seus membros o interesse em manter essas interações ativas. Howard Rheingold (1996), um dos pioneiros na utilização do termo "comunidade virtual", busca caracterizar as relações estabelecidas pelos sujeitos no ciberespaço para além das dimensões de sociabilidade, acrescendo aí uma dimensão estratégica. Por esse motivo, também é possível encontrar perfis de ativistas, organizações e coletivos com postagens de resistência e denúncia que objetivam, em última instância, gerar visibilidade e assim promover o reconhecimento e adesão de outros sujeitos que se identificam com suas demandas. No caso deste ensaio, chamamos a atenção para aqueles que se referem à luta pela garantia dos direitos das pessoas com deficiência, em especial, as mulheres.

Iniciado em 21 de setembro de 2018, o Coletivo Feminista Helen Keller éformado apenas por mulheres com deficiência, que tiveram como uma das principais motivações o desejo de se organizar para ocupar espaços com suas pautas políticas construídas a partir de uma perspectiva socialista, feminista e interseccional, mantendo alianças importantes com outros movimentos e coletivos, uma vez que reconhecem a relação do capacitismo com machismo, racismo, LGBTfobia e demais sistemas de opressão. De acordo com o guia Mulheres com Deficiência: Garantia de Direitos para Exercício da Cidadania,

A data foi escolhida por ser o Dia Nacional de Luta da Pessoa com Deficiência, que surgiu por iniciativa do movimento de pessoas com deficiência e, pela proximidade com a

3 "[...] fundamentally linked to social, cultural, economic, and political processes and structures within which mobility is embedded and enacted." 
primavera, simboliza a renovação. Um dos grandes responsáveis pela data de resistência foi Cândido Pinto de Melo, militante na luta pela democracia e pela inclusão das pessoas com deficiência. Cândido sofreu um atentado que o tornou paraplégico em 1969, enquanto presidia a União Estadual dos Estudantes de Pernambuco (UEP). A resistência à ditadura militar, que o levou a vivenciar a deficiência, também lhe ensinou sobre a importância da luta organizada, a busca pela inclusão e participação plena na sociedade. Esse simbólico 21 de setembro demarca nosso compromisso em defesa da democracia, que tarda a chegar a todas nós, e o enfrentamento ao silenciamento imposto às mulheres com deficiência, onde pautas importantes, como garantia de direitos sexuais, direitos reprodutivos e uma vida livre de violências, sempre foram deixados para depois. O CFHK é composto por mais de 50 integrantes que estão nas 5 regiões do país. Temos atuação, em parceria com outras entidades, no controle social, na execução de projetos, participação em eventos e manifestações e no desenvolvimento de campanhas virtuais pelas redes sociais Facebook, Instagram e Blogger, onde temos mais de 3.300 seguidoras(es). (COLETIVO FEMINISTA HELEN KELLER, 2020d, p. 9).

Na mesma data, o Coletivo lançou nas plataformas de redes sociais digitais seu manifesto - com diretrizes, metas, objetivos e pautas principais - que seria, posteriormente, entregue a cada integrante que demonstrasse interesse em compor o grupo. Disponível para download, nele podemos encontrar definições sobre deficiência, capacitismo e os impactos provocados pela invisibilidade social e pelo isolamento na vida das mulheres com deficiência. Nesse sentido, o coletivo busca, em seu manifesto, promover uma sensibilização acerca das relações de opressão e desrespeito cotidianamente vivenciadas pelas mulheres.

É importante entender que se morre por ser mulher e se vivencia a deficiência pelo mesmo motivo. Abortos precários, violência obstétrica e violência misógina são alguns fatores que apontam o fato de haver uma feminização da deficiência. Precisamos também compreender o impacto do sistema capitalista sobre nossos corpos, já que esse sistema não nos compreende como rentáveis/exploráveis, nos submetendo assim ao "descarte" em vida, negando nossa existência através de barreiras ao mercado de trabalho, educação, saúde e demais direitos fundamentais. Entre esses direitos violados, estão os sexuais e reprodutivos, através de esterilizações compulsórias e abortos indesejados, devido a princípios da eugenia, que consideram que também reproduziremos corpos incapazes à exploração. (COLETIVO FEMINISTA HELEN KELLER, 2019, p. 2).

No entanto, é preciso dar conta de que existem muitas dimensões do feminino e que a tentativa de colocá-lo em uma única identidade, ainda que com o objetivo de mobilizar sentidos em torno da luta por direitos, pode ser uma forma de opressão. Judith Butler (2018) nos apresenta uma crítica à construção feminista de um 'Sujeito', uma representação de uma identidade feminina estável sustentada por alguns movimentos feministas para situar suas reivindicações contra as opressões do patriarcado.

Porém, tanto os discursos, quanto a formação deste 'sujeito' são constituídos por elementos corponormativos e, por essa razão, não representam as dimensões afetivas e realidades sociais de mulheres cuja existência é marcada por situações de vulnerabilidades, provocadas pela falta de recursos econômicos para tratamentos de saúde adequados, moradia em locais com segurança, emprego estável, educação para seus filhos e alimentação diária, por exemplo. Essa crítica da autora nos permite refletir sobre as exigências apresentadas pelo Coletivo, como também entender as diferenças de gênero como forças discursivas que orbitam ao redor da binaridade e hierarquias sexuais dos corpos (BUTLER, 2018, p. 20).

Ao sustentar que a experiência da mulher com deficiência parte de uma triangulação entre as categorias de homem e mulher, a autora Rosemarie Garland-Thomsom (1997) defende a maneira como essa forma de ver o corpo com deficiência autoriza olhares de curiosidade, estranhamento e como isso interfere na autoestima dessas mulheres e no modo como elas lidam com determinados comportamentos considerados femininos, uma vez que, "imaginada como a antítese da mulher normal, a figura da mulher com deficiência 
é, assim, ambiguamente posicionada dentro e fora da categoria de mulher" (GARLAND-THOMSON, 1997, p. 29, tradução nossa) $)^{4}$.

Buscando tensionar algumas questões trazidas pela perspectiva do corpo da mulher com deficiência, atravessadas pelas dimensões de vida e morte que a Covid-19 trouxe para nós, traremos aqui narrativas de mulheres que participaram de uma campanha de compartilhamento de informações sobre saúde nas redes.

Presente no Brasil desde 2007, a organização não-governamental Artigo 19 realiza seu trabalho na defesa ao direito de liberdade de expressão, acesso à informação e garantia de direitos humanos mantendo seu comprometimento com o $19^{0}$ artigo ${ }^{5}$ da Declaração Universal dos Direitos Humanos, referência para a escolha do nome. Com escritório em São Paulo, a ONG realiza suas ações baseada nos cinco pilares para liberdade de expressão, de acordo com o Global Expression Report 2018/19, sendo elas:

\begin{abstract}
Espaço Cívico: espaço de participação no debate público e na ação política; Digital: a capacidade de se expressar via internet; Mídia: o ambiente propício para veículos e publicações; Proteção: a proteção e a segurança daqueles que se expressam; eTransparência: a capacidade das pessoas de obter informações e forçar a responsabilidade dos detentores de poder (GLOBAL EXPRESSION REPORT 2018/19, 2019, tradução nossa) ${ }^{6}$.
\end{abstract}

Em maio de 2020, a Artigo 19 organizou uma campanha com as hashtags \#CompartilheInformação \#CompartilheSaúde para divulgar informações confiáveis sobre saúde, cuidados durante a pandemia e liberdade de expressão, ampliando o debate em torno dos impactos causados pela Covid-19. Para isso, foi aberto um edital de seleção de organizações, coletivos e comunicadores interessados em contribuir com a formação de uma rede de diálogos e encontros. Dentre os 23 selecionados, o Coletivo Feminista Helen Keller teve a oportunidade de participar das ações durante os meses de junho, julho e agosto de 2020, apresentando lives com mulheres com deficiência, integrantes e não-integrantes do Coletivo, debatendo temas importantes para saúde feminina como direito à maternidade, ao aborto, experiências com cuidado, violência doméstica e sexualidade.

Separamos uma postagem (Figura 1) do dia 24 de julho de 2020 no perfil do Coletivo no Instagram, uma imagem com um texto apresentando as datas das lives que seriam realizadas no mês, convidando os usuários da rede a participarem dos eventos. A legenda nos despertou o interesse por revelar as implicações da ausência de acessibilidade nos conteúdos de prevenção à Covid-19, isto é, vídeos e lives sem tradutores de Libras, imagens sem texto alternativo para pessoas com deficiência visual e falta de acessibilidade de plataformas de redes sociais e aplicativos.

\footnotetext{
4 (...) imagined as the antithesis of the normal woman, the figure of the disabled female is thus ambiguously positioned both inside and outside the category of woman".

5 "Todo ser humano tem direito à liberdade de opinião e expressão; esse direito inclui a liberdade de, sem interferência, ter opiniões e de procurar, receber e transmitir informações e ideias por quaisquer meios e independentemente de fronteiras" (ONU, 1948).

6 "Civic Space: the space to participate in public debate and political action; Digital: the ability to express oneself via the internet; Media: the enabling environment for outlets and publications; Protection: the safety and security of those who express themselves; and Transparency: people's ability to gain information and force accountability from powerholders."
} 


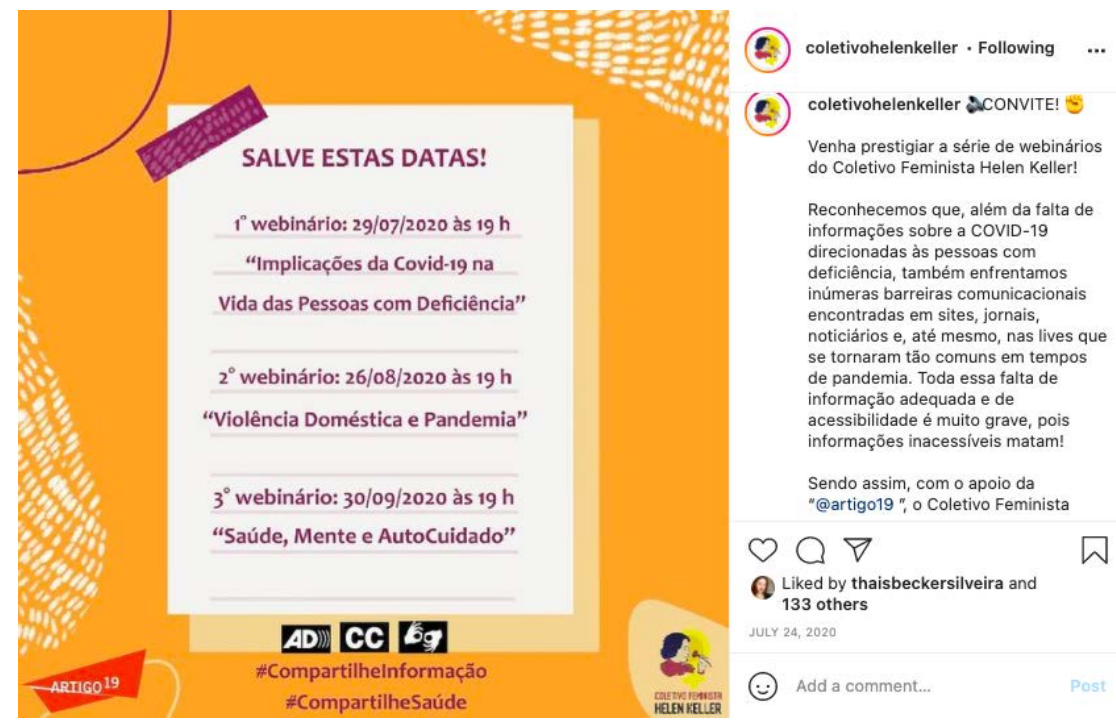

Figura 1 - Agenda Webinários

Fonte: Coletivo Feminista Helen Keller, 2020c.

Reconhecemos que, além da falta de informações sobre a COVID-19 direcionadas às pessoas com deficiência, também enfrentamos inúmeras barreiras comunicacionais encontradas em sites, jornais, noticiários e, até mesmo, nas lives que se tornaram tão comuns em tempos de pandemia. Toda essa falta de informação adequada e de acessibilidade é muito grave, pois informações inacessíveis matam! Sendo assim, com o apoio da “@artigo19”, o Coletivo Feminista Helen Keller de Mulheres com Deficiência participará da Campanha \#CompartilheInformação \#CompartilheSaúde e realizará três webinários que serão transmitidos em nossa página no Facebook e contarão com o audiodescrição, legendagem ao vivo e intérprete de Libras. (COLETIVO FEMINISTA HELEN KELLER, 2020c).

As barreiras comunicacionais também interferem no enfrentamento à violência doméstica sofrida por mulheres com deficiência, pois ao permanecerem expostas e necessitarem da mediação de outros para realizarem seus cuidados pessoais, essas mulheres podem encontrar dificuldades de denunciar seus algozes. Em 2006, foi promulgada no Brasil a lei Maria da Penha (BRASIL, 2006) em defesa das mulheres vítimas de agressões físicas, psicológicas, sexuais, patrimoniais e morais consideradas como violação dos direitos humanos. No feed do perfil, no dia 7 de agosto de 2020, além do post que integrava as ações que buscavam conscientizar sobre a violência contra a mulher, foi feita também uma postagem (Figura 2) em homenagem a Maria da Penha, responsável por todo processo e luta que resultou na criação da lei. A farmacêutica tornou-se mulher com deficiência após uma tentativa de feminicídio perpetrada pelo seu cônjuge, que atirou em suas costas enquanto dormia, causando uma lesão em sua coluna. 

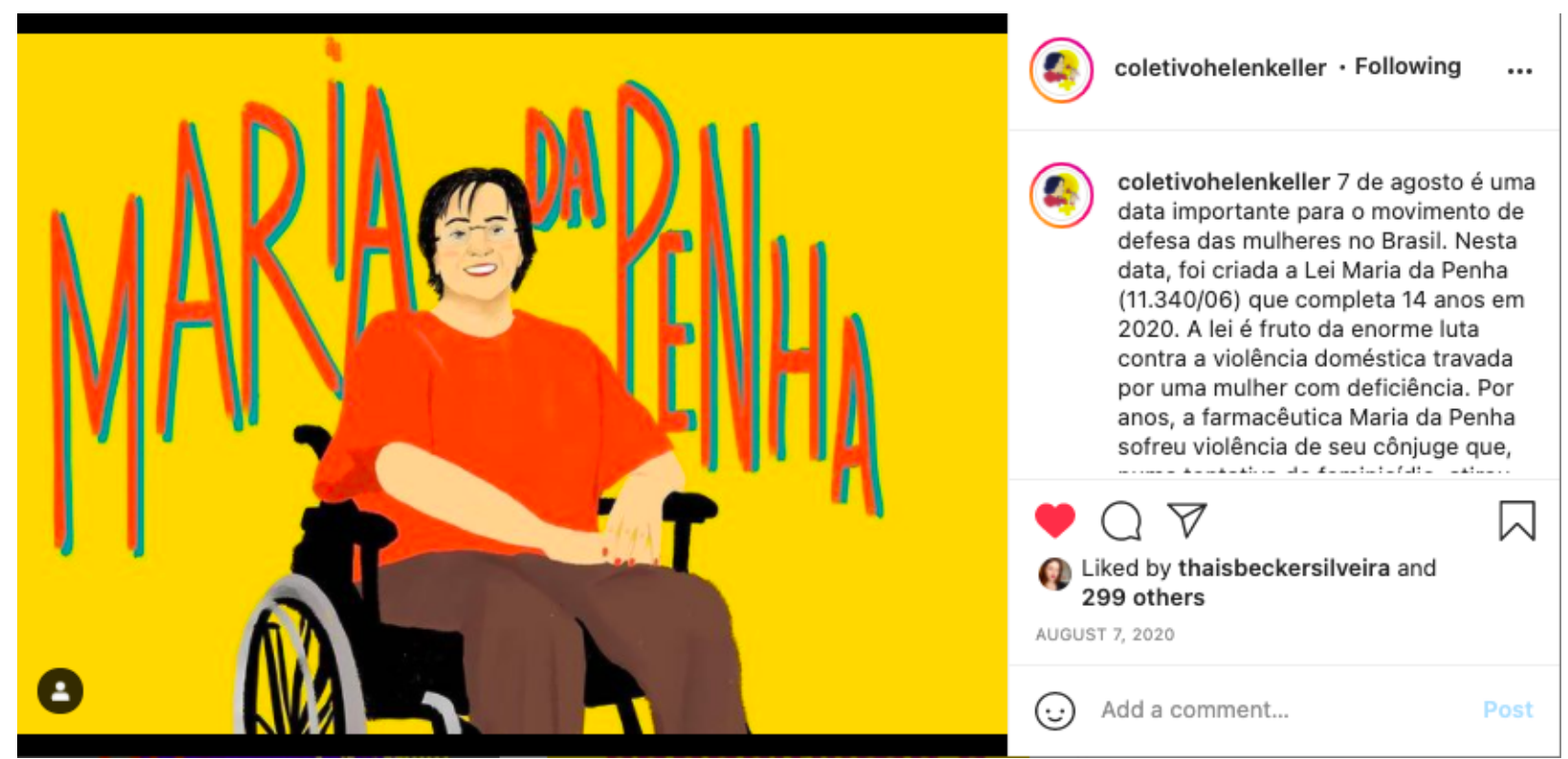

Figura 2 - Homenagem a Maria da Penha

Fonte: Coletivo Feminista Helen Keller, 2020b.

Para encerrar a campanha, no dia 30 de agosto de 2020, o Coletivo realizou uma live no youtube (WEBINÁRIO..., 2020) com a participação de Izabel de Loureiro Maior, mulher com deficiência, mestre em Medicina Física e Reabilitação pela UFRJ, considerada um dos principais nomes do movimento de pessoas com deficiência pela sua atuação, de 2002 a 2011, como secretária nacional de Promoção dos Direitos da Pessoa com Deficiência da Secretaria de Direitos Humanos da Presidência da República. O tema do webinário foi Mente, Saúde e Autocuidado e, para isso, foi utilizado um vídeo com legenda e tradução em Libras para divulgação (Figura 3).

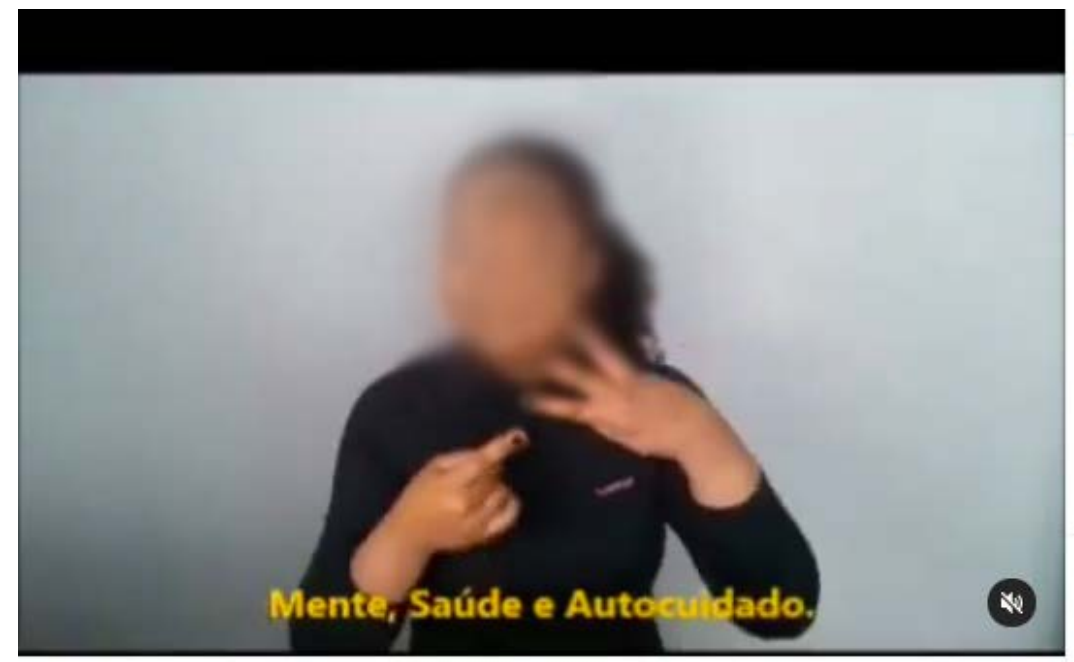

(i) For information about CovID-19, visit saude.gov.br. coletivohelenkeller - Following $\quad \ldots$

\#Compartılneintormaçao \#CompartilheSaúde

Vem aí, o nosso último webnário de informações com foco nas pessoas com deficiência e Covid19, com acessibilidade comunicacional: libras, audiodescrição e legendagem.

Será no próximo dia 30 , quarta-feira, às 19 h. Não perca!

\#Paratodasverem: vídeo começa com

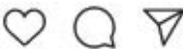

271 views

SEPTEMBER 25, 2020

Figura 3 - Webinário Acessível Mente, Saúde e Autocuidado Fonte: Coletivo Feminista Helen Keller, 2020a.

Em agosto, antes deste encontro, o Coletivo comemorou dois anos de formação com depoimentos de integrantes em uma sequência de postagens. Notamos nesses relatos a relevância de um espaço de debate, construção política e organização feminista para construir um sentimento de pertencimento nas mulheres com 
deficiência que compõem o grupo. Nos demais conteúdos do perfil notamos, entre outras temáticas frequentes, o esforço em denunciar a invisibilidade de mulheres com deficiência tanto no feminismo quanto nos demais movimentos sociais, o qual nos permite notar o aspecto estrutural do capacitismo em pautas consideradas essenciais como racismo, sexismo, machismo, entre outros.

Diante do exposto, compreendemos que a experiência com deficiência oferece algumas perspectivas que podem contribuir para a vivência das pessoas sem deficiência, na medida em que observamos algumas práticas adotadas durante a pandemia. Para aqueles com acesso a uma infraestrutura, tanto em termos de equipamento e rede quanto em relação às questões da acessibilidade, trabalhos remotos em regime home office, aulas on-line, compras virtuais e o distanciamento foram incorporados ao cotidiano. Nesses cenários, vimos se constituírem novas redes afetivas, outras relações com o tempo e, principalmente, pontes de diálogos e mediações possíveis que se deram a ver a partir de dinâmicas específicas de imobilidades (isolamento social) que foram impostas os sujeitos.

Desde 2018, o Coletivo Feminista Helen Keller conta com a participação on-line de suas integrantes mulheres com deficiência de diferentes regiões do país - compartilhando informações sobre a feminização da deficiência e promovendo encontros com outros coletivos feministas em suas redes sociais, trazendo para o centro dos debates as implicações das barreiras arquitetônicas, atitudinais, tecnológicas e de mobilidade provocadas pela deficiência. Observando os cuidados em promover uma comunicação acessível, o Coletivo ainda estimula a adoção de novas práticas de acessibilidade virtual como descrição de imagens, legendas nos vídeos e tradutores de Libras nos webinários.

A parceria com a ONG Artigo 19 favoreceu a divulgação dessas informações, mas também promoveu um espaço de fala que possibilitou a essas mulheres com deficiência trazerem suas experiências pessoais, manifestarem seus anseios, assumirem o papel de protagonistas de suas lutas. Dessa forma, foi possível às pessoas sem deficiência conhecer e, principalmente, ter contato com os obstáculos estruturais evidenciados pelo isolamento social.

Finalizamos com a compreensão da potência dos fluxos afetivos construídos a partir de circuitos virtuais para oportunizar o agenciamento de pessoas em situação de vulnerabilidade, mas sinalizamos a importância dos movimentos da sociedade civil para pressionar entidades do governo a promover medidas e estratégias que transformem a experiência com a mobilidade, tornando os espaços sociais, tanto on como off-line, mais igualitários, com critérios de justiça e garantia de direitos humanos para todos os setores da sociedade de modo a diminuir os impactos provocados por outras crises, de dimensões globais, que possam surgir nos anos a seguir.

\section{REFERÊNCIAS}

BRASIL. Presidência da República, Secretaria-Geral. Lei n 11.340, de 7 de agosto de 2006. Cria mecanismos para coibir a violência doméstica e familiar contra a mulher... Diário Oficial da União, Brasília, DF, 8 ago. 2006. Disponível em:http://www.planalto.gov.br/ccivil 03/ Ato2004-2006/2006/Lei/ L11340.htm. Acesso em: 9 mar. 2021.

BUTLER, Judith. Problemas de gênero: feminismo e subversão da identidade. Tradução: Renato Aguiar. Rio de Janeiro: Civilização Brasileira, 2018.

COSTA, Rogério da. On a new community concept: social networks, personal communities, collective intelligence. Interface - Comunicação, Saúde, Educação, Botucatu, v. 9, n. 17, p. 235-248, 2005. DOI: https://doi.org/10.1590/S1414-32832005000200003. Disponível em: https://www.scielo.br/j/icse/a/ gx3Z8FPYVqJYdN6kDZ3HyfM/abstract/?lang=en. Acesso em: 4 ago. 2021.

COLETIVO FEMINISTA HELEN KELLER. \#Compartilhelnformação \#CompartilheSaúde [...]. [S. I.], 25 set. 2020a. Instagram: @coletivohelenkeller. Disponível em: https://www.instagram.com/p/CFk9 qwHn2s/. Acesso em: 9 mar. 2021.

COLETIVO FEMINISTA HELEN KELLER. 7 de agosto é uma data importante para o movimento de 
defesa das mulheres no Brasil. [...]. [S. I.], 7 ago. 2020b. Instagram: @coletivohelenkeller. Disponível em: https://www.instagram.com/p/CDI7uJxp1NCl. Acesso em: 9 mar. 2021.

COLETIVO FEMINISTA HELEN KELLER. Convite! [...]. [S. I.], 22 jul. 2020c. Instagram: @ coletivohelenkeller. Disponível em: https://www.instagram.com/p/CDCXpXpJCR-I. Acesso em: 2 mar. 2021.

COLETIVO FEMINISTA HELEN KELLER. Manifesto do Coletivo Feminista Helen Keller. [S. I.], 19 set. 2019. Disponível em: https://coletivofeministahelenkeller.wordpress.com/2019/09/19/manifesto-coletivofeminista-helen-keller/ Acesso em: 2 mar. 2021.

COLETIVO FEMINISTA HELEN KELLER. Mulheres com deficiência: garantia de direitos para exercício da cidadania. [S. I.]: A Organização, 2020d. Disponível em: https://drive.google.com/file/d/1sS 5cg5sL0O Ns2qtDlk4v8sNgCcUprg7/view. Acesso em: 4 mar. 2021.

CONVENÇÃO SOBRE OS DIREITOS DAS PESSOAS COM DEFICIÊNCIA: Protocolo Facultativo à Convenção sobre os Direitos das Pessoas com Deficiência: Decreto Legislativo no 186, de 09 de julho de 2008: Decreto no 6.949, de 25 de agosto de 2009: Declaração Universal dos Direitos Humanos. Vitória: Ministério Público do Trabalho, 2014. 124p. Disponível em http://www.pcdlegal.com.br/convencaoonu/wpcontent/themes/convencaoonu/downloads/ONU Cartilha.pdf. Acesso em: 2 mar. 2021.

DINIZ, Debora; MEDEIROS, Marcelo; SQUINCA, Flávia. Reflexões sobre a versão em português da Classificação Internacional de Funcionalidade, Incapacidade e Saúde. Cadernos de Saúde Pública, Rio de Janeiro, v. 23, n. 10, p. 2507-2510, 2007. DOI: https://doi.org/10.1590/S0102-311X2007001000025. Disponível em: https://www.scielo.br/j/csp/a/TgD9wYJLfpXPnG4KSP36rZK/abstract/?lang=pt. Acesso em: 3 ago. 2021.

GARLAND-THOMSON, Rosemarie. Extraordinary bodies: figuring physical disability in American culture and literature. New York: Columbia University Press, 1997.

GLOBAL EXPRESSION REPORT 2018/2019: the state of freedom of expression around the world. Article 19, [s. I.], 2 dez. 2019. Disponível em: https://www.article19.org/reader/global-expressionreport-2018-19/. Acesso em: 4 mar 2021.

INSTITUTO BRASILEIRO DE GEOGRAFIA E ESTATÍSTICA (IBGE). Censo demográfico 2010: características gerais da população, religião e pessoas com deficiência. Rio de Janeiro: IBGE, 2012. Disponível em: https://biblioteca.ibge.gov.br/visualizacao/periodicos/94/cd_2010_religiao_deficiencia.pdf. Acesso em: 3 ago. 2021.

KAUFMANN, Vincent; BERGMAN, Manfred Max; JOYE, Dominique. Motility: mobility as capital. International Journal of Urban and Regional Research, [s. I.], v. 28, n. 4, p. 745-756, 2004. DOI: https://doi.org/10.1111/j.0309-1317.2004.00549.x. Disponível em: https://onlinelibrary.wiley.com/ doi/10.1111/j.0309-1317.2004.00549.x. Acesso em: 5 fev. 2021.

ORGANIZAÇÃO DAS NAÇÕES UNIDAS (ONU). Declaração Universal dos Direitos Humanos. Genebra: A Organização, 1948. Disponível em: https://www.unicef.org/brazil/declaracao-universal-dosdireitos-humanos. Acesso em: 9 mar. 2021.

ORGANIZAÇÃO PAN-AMERICANA DE SAÚDE (OPAS). Folha informativa sobre COVID-19. Brasília, DF: A Organização, [2020]. Disponível em: https://www.paho.org/pt/covid19. Acesso em: 1 mar. 2021.

PESSOA, Sônia. Imaginários sociodiscursivos sobre a deficiência: experiências e partilhas. Belo Horizonte: PPGCOM, 2018.

RECUERO, Raquel. Redes sociais na internet. Porto Alegre: Sulina, 2009. (Coleção Cibercultura).

RHEINGOLD, Howard. La comunidad virtual: una sociedad sin fronteras. Barcelona: Gedisa Editorial, 1996. (Colección Limites de La Ciência).

ROUBICEK, Marcelo. O emprego no Brasil durante a pandemia em 3 pontos. Nexo, São Paulo, 28 jan. 2021. Expresso. Disponível em: https://www.nexojornal.com.br/expresso/2021/01/28/O-emprego-noBrasil-durante-a-pandemia-em-3-pontos. Acesso em: 1 mar. 2021. 
Reciis - Revista Eletrônica de Comunicação, Informação \& Inovação em Saúde, Rio de Janeiro, v. 15, n. 3, p.776-789, jul.-set. 2021 [www.reciis.icict.fiocruz.br] e-ISSN 1981-6278

SANTOS, Milton. Por uma outra globalização: do pensamento único à consciência universal. 10. ed. Rio de Janeiro: Record, 2003.

SANTOS, Milton. A Natureza do espaço: técnica e tempo, razão e emoção. 4.ed. São Paulo: EdUSP, 2012.

SHELLER, Mimi. Mobility justice: the politics of movement in the age of extremes. Londres: Verso, 2018.

SHELLER, Mimi; URRY, John. The new mobilities paradigm. Environment and Planning, [s. I.], v. 38, n. 2, p. 207-226, 2006. DOI: https://doi.org/10.1068\%2Fa37268. Disponível em: https://journals.sagepub. com/doi/10.1068/a37268. Acesso em: 18 ago. 2021

URRY, John. Mobilities. Londres: Routledge, 2007.

WEBINÁRIO: Mente, Saúde e Autocuidado. [S. l., s. n.]: 2020. 1 vídeo (67 min). Transmitido pelo canal Coletivo Feminista Helen Keller. Disponível em: https://youtu.be/HpLUGcq2NRc. Acesso em: 9 mar. 2021. 